\title{
Direct Observation of Bacterial Exopolysaccharides in Dairy Products Using Confocal Scanning Laser Microscopy
}

\author{
Ashraf N. Hassan, ${ }^{\star}$ Joseph F. Frank, ${ }^{\star}$ and Karsten B. Qvist $†$ \\ *Department of Food Science and Technology, Athens, GA 30602, USA \\ †Center for Advanced Food Studies, and Department of Dairy and Food Science, \\ The Royal Veterinary and Agricultural University, Rolighedsvej 30, \\ DK-1958 Frederiksberg C, Denmark
}

\begin{abstract}
The objective of this work was to develop a methodology for direct visualization of bacterial exopolysaccharides (EPS) in fully hydrated dairy products. The new method involved staining EPS with wheat germ agglutinin labeled with Alexa fluor 488 or staining with concanavalin A 488. Samples were observed using confocal scanning laser microscopy. Distribution of EPS produced by Lactococcus lactis (CHCC 3367), a combination of Streptococcus thermophilus (CHCC 3534) and Lactobacillus delbrueckii ssp. bulgaricus (CHCC 769) and Lactobacillus delbrueckii ssp. bulgaricus RR in milk was compared in stirred and unstirred fermented milk. The EPS and proteins were observed as distinct entities, with EPS present in the protein network pores. EPS was observed in greater amounts in milk fermented by the ropy $L$. lactis culture than in milk fermented by the less ropy strain of $S$. thermophilus. Stirring the fermented milk caused aggregation of EPS into more extended structures. The more ropy the culture, the longer and larger the strands formed during stirring. The method was also applied to Feta cheese made with an EPS-producing strain of $S$. thermophilus. EPS was observed in the cheese as thick sheets filling pores in the protein network.
\end{abstract}

(Key words: exopolysaccharide, confocal scanning laser microscopy, yogurt)

Abbreviation key: CSLM = confocal scanning laser microscopy, EPS = exopolysaccharides, $\mathbf{S E M}$ = scanning electron microscopy.

\section{INTRODUCTION}

Exopolysaccharide-(EPS) producing cultures are widely used to improve the physical properties of fermented milk. However, textural and rheological studies

Received November 27, 2001.

Accepted January 14, 2002.

Corresponding author: J. F. Frank; e-mail: frank@flavor. fst.uga.edu. have not fully provided an explanation for how EPS functions in fermented milk products.

Direct microscopic observation is potentially a useful and simple approach for obtaining information that would help in understanding the function of EPS in dairy products. Scanning electron microscopy (SEM) has been extensively used to observe milk fermented by EPS-producing cultures (Kalab et al. 1983; Schellhaass and Morris, 1985; Teggetz and Morris, 1990). With SEM, EPS appears as filaments associated with bacterial cells and the casein network. EPS is highly hydrated and cannot be chemically fixed, so this filamentous appearance results from the EPS structure collapsing during dehydration before SEM observation (Kalab, 1993).

Lectins are carbohydrate-binding proteins and several of their fluorescent conjugates are commercially available. Their binding specificity allows direct visualization of EPS in structures such as biofilms (Leriche et al., 2000). Two such lectins, concanavalin A (specific binding to $\alpha$-mannopyranosyl and $\alpha$-glucopyranosyl residues) and wheat germ agglutinin (specific binding to $N$-acetyl glucosamine and $N$-acetylneuraminic acid residues) are used in this study to visualize EPS in dairy products. Hassan et al. (1995) developed a technique for using CSLM in studying fermented milk microstructure in its natural fully hydrated state. The objective of the present work was to apply this technique in combination with staining using conjugated lectin to directly observe EPS in fully hydrated dairy products without disturbing the structural integrity of the gel. Cultured milk and feta cheese were selected as representative products.

\section{MATERIALS AND METHODS}

Fermented milk was made from low heat rehydrated skimmed milk ( $11 \% \mathrm{wt} / \mathrm{vol}$ ) steamed for $12 \mathrm{~min}$, cooled, and kept in the refrigerator overnight. Milk was warmed to $40^{\circ} \mathrm{C}$, inoculated with $2 \%$ each of encapsulated ropy Streptococcus thermophilus CHCC 3534 (Chr. Hansen, Denmark) and nonencapsulated nonropy 

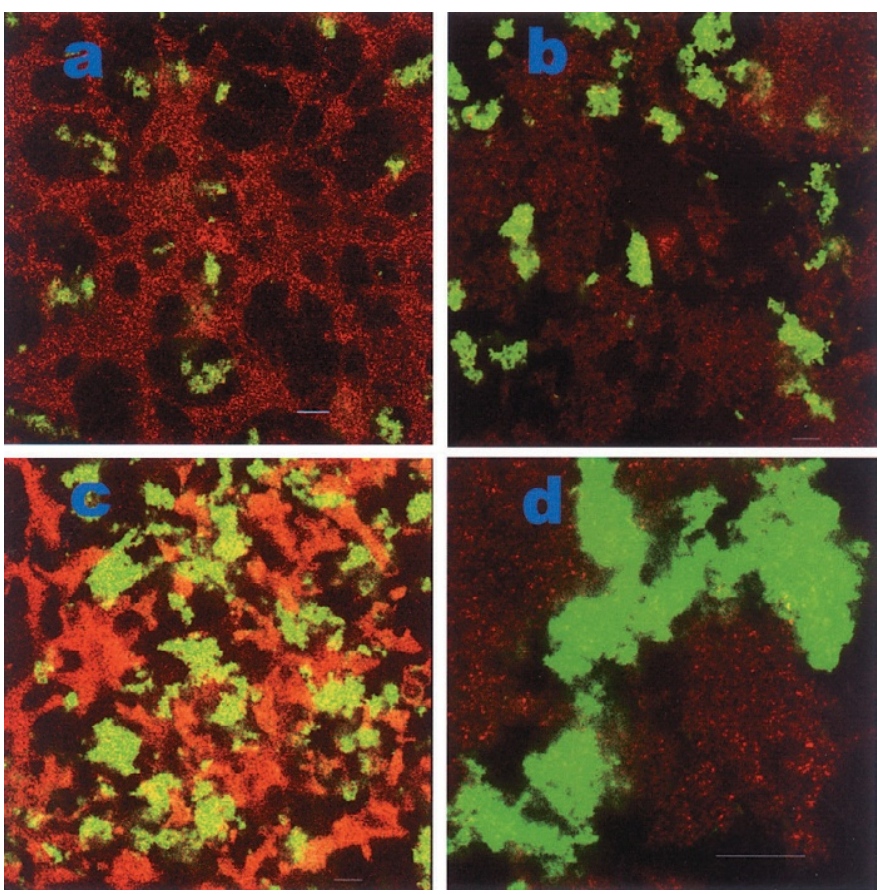

Figure 1. Distribution of exopolysaccharide (green) within structure of fermented milk. A. Milk fermented by ropy Streptococcus thermophilus CHCC 3534 and nonropy Lactobacillus delbrueckii ssp. bulgaricus CHCC 769. B. Milk fermented by ropy S. thermophilus CHCC 3534 and nonropy Lactobacillus delbrueckii ssp. bulgaricus CHCC 769 after stirring. C. Milk fermented by ropy Lactococcus lactis CHCC 3367. D. Milk fermented by ropy Lactococcus lactis CHCC 3367 after stirring. Wheat germ agglutinin was used to stain EPS. Bar = $10 \mu \mathrm{m}$.

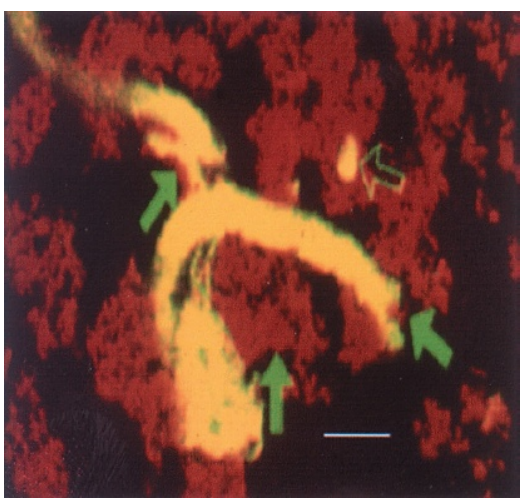

Figure 2. Milk fermented by Lactobacillus delbrueckii ssp. bulgaricus RR after stirring. Closed head arrows point to protein aggregates (red) and open head arrows point to EPS (yellow). Concanavalin A was used to stain EPS. Bar $=25 \mu \mathrm{m}$.

Lactobacillus delbrueckii ssp. bulgaricus CHCC 769 (Chr. Hansen), 4\% of encapsulated ropy Lactococcus lactis CHCC 3367 (Chr. Hansen), 4\% of encapsulated ropy Lb. Delbrueckii ssp. bulgaricus RR (University of Minnesota), or $2 \%$ each of nonencapsulated nonropy $S$.

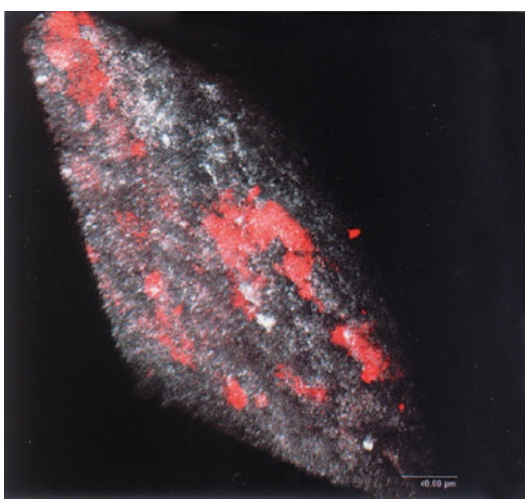

Figure 3. Volumetric image showing distribution of exopolysaccharide (red) within protein matrix (white) of feta cheese. Concanavalin A was used to stain EPS produced by Streptococcus thermophilus 3855 used in making the cheese.

thermophilus (CHCC2136) and nonencapsulated nonropy Lb. Delbrueckii ssp. bulgaricus CHCC 769 (control) and incubated at 37 or $25^{\circ} \mathrm{C}\left(25^{\circ} \mathrm{C}\right.$ for Lc. Lactis $)$. After coagulation, milk was kept at $5^{\circ} \mathrm{C}$ for $24 \mathrm{~h}$ until the microscopic observation the following day. Nonfat feta cheese was made by adding $2 \%$ of an encapsulated nonropy culture of $S$. thermophilus 3855 (RhônePoulenc Dairy Ingredients, Madison, WI) to rehydrated nonfat milk pasteurized at $63^{\circ} \mathrm{C}$ for $30 \mathrm{~min}$ and cooled to $35^{\circ} \mathrm{C}$. Milk was allowed to ripen until the $\mathrm{pH}$ of 6.1 was obtained. The protocol described by Katsiari and Voutsinas (1994) for making feta cheese was then followed.

Wheat germ agglutinin conjugated with Alexafluor 488 (Molecular Probes Inc., Eugene, OR), and concanavalin A 488 (Molecular Probes Inc.) were used to label EPS. Concanavalin A stock solution was prepared by dissolving $5 \mathrm{mg}$ in $5 \mathrm{ml}$ of $0.1 \mathrm{M}$ sodium bicarbonate at $\mathrm{pH} 8.3$ and stored at $-20^{\circ} \mathrm{C}$. Working solution was prepared by diluting stock solution to 1:20 using whey obtained from fermented milk to avoid changes in $\mathrm{pH}$ or osmolarity. For wheat germ agglutinin, the working solution was prepared by diluting the stock solution (1 $\mathrm{mg}$ of the dye in $1 \mathrm{ml}$ of phosphate buffer at $\mathrm{pH}$ 6.8) to 1:5 using fermented milk whey. Some drops of the dye were added to an undisturbed fermented milk sample and left for $1 \mathrm{~h}$ at $5^{\circ} \mathrm{C}$ to allow diffusion. Another sample was gently stirred after adding the dye. A small piece of each of the unstirred and stirred stained samples were carefully transferred to chambered coverglasses (Nalge Nunc International Corp., Naperville, IL) to be observed with an inverted Leica TCS 4D confocal scanning laser microscope (CSLM) with a Leitz DM RB/E* (Leica, Glostrup, Denmark) fitted with an $\mathrm{Ar} / \mathrm{Kr}$ laser. Some samples were observed with a Bio-Rad CSLM (BioRad Inc., Hemel Hempstead, UK) with a $60 \times$ objec- 
tive $(\mathrm{NA}=1.4)$. Other samples were tested using a Leica CSLM (Leica Microsystems, Heidelberg, Germany).

To stain EPS in feta cheese, a portion of cheese was centrifuged to collect whey, which was then used to dilute the stock solution of the concanavalin $\mathrm{A}$ to be used in the staining procedure. Dye was added to thin slices of cheese (about $3 \mathrm{~mm}$ ), which were then kept at $5^{\circ} \mathrm{C}$ for $1 \mathrm{~h}$. Cheese pieces were then rinsed with whey to remove excess stain and observed by CSLM. Whey obtained from the same batch of the tested product was used to dilute dye to avoid changes in $\mathrm{pH}$ or osmolarity. The three-dimensional image was reconstructed from optical sections using Leica Confocal Software Version 2 build 0368 . When collecting the $\mathrm{z}$-series, distance between optical sections was kept equal to the voxel size.

The protein network was observed using the reflectance mode of the confocal microscope as described by Hassan et al. (1995). Excitation and emission wavelengths for both concanavalin A and wheat germ agglutinin are 495 and $519 \mathrm{~nm}$, respectively.

\section{RESULTS AND DISCUSSION}

The two lectins used in our methodology were selected based on preliminary screening. A nonencapsulated nonropy strain of S. thermophilus (CHCC2136) was employed as a control. This control showed only slight indications of EPS production by the lectin labeling method.

CSLM of samples stained with fluorescent-labeled lectin, allowed visualization of the fully hydrated EPS within fermented milk structure (Figures 1 and 2). Figure 1a and c show the distribution of EPS materials produced by a moderately ropy strain of $S$. thermophilus and ropy strain of Lactococcus within the undisturbed protein network. Exopolysacharides and protein appear as distinct entities, with EPS present in the pores of the protein network. EPS was observed in greater amounts in milk fermented by the ropy Lc. Lactis culture compared with milk fermented by the less ropy strain of $S$. thermophilus. In addition, larger masses of EPS were produced by the ropy Lc. Lactis (Figure 1c) compared with those produced by the less ropy strain of S. thermophilus CHCC 3534 (Figure 1a). Whereas previous research has indicated that there is no direct relationship between the amount of EPS produced and ropiness associated with a culture (van Marle and Zoon, 1995), molecular characteristics of the EPS such as those influencing the size of the polymer in solution (i.e., radius of gyration) determine the effectiveness of EPS as a thickening agent (Kleerebezem et al., 1999). It is therefore possible that such molecular characteristics may be related to the size of EPS masses as observed in this study.
Stirring broke the original continuous protein network (Figure 1a and c), creating a new network of entangled protein aggregates (Figure $1 \mathrm{~b}$ and d). Stirring did not cause a mixing of the protein and EPS, but rather a segregation of the two components, causing the EPS to become collected in much more extensive structures. It is thus clear that stirring facilitated creation of more EPS-EPS interactions. Figure 2 shows EPS in stirred yogurt fermented by ropy $L b$. Delbrueckii ssp. bulgaricus RR. With this culture, which is the most ropy used in this study, we observed the longest and thickest EPS structures after stirring. Based on the observations in Figures 1 and 2, it thus seems likely that the tendency for EPS to self interact upon stirring, thereby creating extended and more continuous EPS structures through the product is related to observed ropiness.

The appearance of EPS in fermented milk as observed in this study using CSLM differs from that obtained using scanning electron microscopy. SEM shows EPS in yogurt forming a web-like structure within the protein network (Kalab et al., 1983; Schellhauss and Morris, 1985; Teggatz and Morris, 1990). In those images, EPS appears as filaments attached to bacterial cells and protein network. This filamentous appearance is probably due to dehydration of EPS resulting from sample preparation techniques (Kalab, 1993). Another difference between the two methods is that bacterial cells are not visualized by the lectin staining method we employed.

EPS was visualized in feta cheese as thick masses filling pores within the protein structure (Figure 3). Similar pores were observed by Hassan et al. (1995) in yogurt fermented by the same strain ( $S$. thermophilus 3855). They observed that these pores are formed around bacterial cells as a result of the presence of capsular EPS.

\section{CONCLUSIONS}

Lectin conjugates were successfully used in combination with CSLM to observe bacterial EPS in fully hydrated dairy products. This technique showed that the EPS is produced in thicker masses than those previously reported when conventional scanning electron microscopy was used. EPS and protein appear to be segregated with EPS present in network pores. The more ropy the cultures, the larger amount and size of EPS found. Stirring broke protein network, which facilitated the creation of more EPS-EPS interactions resulting in production of extended EPS structure.

\section{ACKNOWLEDGMENTS}

This research was financially supported by Chr. Hansen, Denmark. Additional support was provided by 
State and Hatch funds allocated to the Georgia agricultural experiments station. We would like to thank Richard Ipsen for valuable discussions throughout the study. We also thank Mark Farmer for suggestions in revising the manuscript.

\section{REFERENCES}

Hassan, A. N., J. F. Frank, M. A. Farmer, K. A. Schmidt, and S. I. Shalabi. 1995. Formation of yogurt microstructure and threedimensional visualization as determined by confocal scanning laser microscopy. J. Dairy Sci. 78:2629-2636.

Kalab, M. 1993. Practical aspects of electron microscopy in dairy research. Food Struct. 12:95-114.

Kalab, M., P. Allan-Wojtas, and B. E. Phipps-Todd. 1983. Development of microstructure in set-style nonfat yogurt. A review. Food Struct. 2:51-66.
Katsiari, M. C., and L. P. Voutsinas. 1994. Manufacture of low fat Feta cheese. Food Chem. 49:53-60.

Kleerebezem, M., R. van Kranenburg, R. Tuinier, I. C. Boels, P. Zoon, E. Looijesteijn, J. Hugenholtz, and W. M. De Vos. 1999. Exopolysaccharides produced by Lactococcus lactis: from genetic engineering to improved rheological properties? Antonie Van Leeuwenhoek 76:357-365.

Leriche, V., P. Sibille, and B. Carpentier. 2000. Use of an enzymelinked lectin sorbent assay to monitor the shift in polysaccharide composition in bacterial biofilms. Appl. Environ. Microbiol. 66:1851-1856.

Schellhaass, S. M., and H. A. Morris. 1985. Rheological and scanning electron microscopic examination of skim milk gels obtained by fermenting with ropy and non-ropy strains of lactic acid bacteria. Food Microstruct. 4:279-287.

Teggatz, J. A., and H. A. Morris. 1990. Changes in the rheology and microstructure of ropy yogurt during shearing. Food Struct. 9: $133-138$.

van Marle, M. E., and P. Zoon. 1995. Permeability and rheological properties of microbially and chemically acidified skim-milk gels. Neth. Milk Dairy J. 49:47-65. 